\title{
Conquistar la igualdad: la coeducación hoy
}

Conquering equality: coeducation today

\author{
Marc Pallarès Piquer \\ e-mail: pallarem@uji.es \\ Universitat Jaume I. España
}

\section{Resumen}

En el presente monográfico se propone entender que la educación supone un contexto idóneo para el avance en la igualdad de oportunidades entre mujeres y hombres. La coeducación se erige en una dimensión social capaz de cuestionar los condicionantes tradicionales de un modelo educativo que, en realidad, no siempre ha sido capaz de distinguir la igualdad de acceso a la educación de lo que se entendía como «la educación para la igualdad de oportunidades»; por eso, a la sociedad (en general) y a las Ciencias Sociales (más en particular), les queda, en el largo camino hacia la coeducación, la tarea de afrontar retos que hagan posible la progresión de decisiones con sentido profesional en las funciones pedagógicas que se tienen que llevar a cabo en cada rincón de nuestros centros educativos. La tarea es, cuanto menos, apasionante, y cada uno de los artículos que componen este monográfico aporta un grano de arena al sentido educativo, constructivo y optimizante de la coeducación.

Palabras clave: coeducación; género; igualdad

\section{Abstract}

In the present monograph it is proposed to understand that education is an ideal context for progress in equal opportunities between women and men. Coeducation is established as a social dimension capable of questioning the traditional conditioning factors of an educational model that, in reality, has not always been able to distinguish equality of access to education from what was understood as "Education for equal opportunities"; for that reason, to society (in general) and to Social Sciences (more in particular), need to face, in the long way to coeducation, challenges that make possible the progression of decisions with professional sense in the pedagogical functions that have to be carried out in every corner of our educational centers. The task is, at least, exciting, and each of the articles that make up this monograph contributes something to the educational, constructive and optimizing sense of coeducation.

Keywords: coeducation; gender; equality

Recibido / Received: 01-05-2019

Aceptado / Accepted: 09-05-2019

Publicación en línea / Published online: 01-07-2019

Cómo referenciar este artículo / How to reference this article:

Pallarès Piquer, M. (2019). Conquistar la igualdad: la coeducación hoy. Tendencias Pedagógicas, 34, pp. 1-4. doi: 10.15366/tp2019.34.001 
Plantearse la publicación de un monográfico sobre coeducación implica asumir un conjunto de demandas comprometidas con la constitución de horizontes sociales de esperanza, sobre todo a partir de la constatación de una serie de críticas (o de situaciones susceptibles de mejora) y, también, en base a la descripción de diferentes escenarios de resistencia del presente.

Las culturas cuentan con paradigmas y órdenes que, de una manera u otra, habitualmente determinan qué es lo masculino y qué es lo femenino. En consecuencia, el género se acostumbra a explicar en consonancia con una construcción cultural que, a partir del sexo, establece los roles, la identidad y los escenarios de acción, de forma segmentada, entre mujeres y hombres (Espejo, 2010). En estas circunstancias y contextos, lo que termina sucediendo es que el género se constituye sobre creencias y prácticas que sugieren (e incluso, en muchas ocasiones, ¿imponen?) cómo tienen que ser los hombres y las mujeres, así como una parte de sus comportamientos, sus sentimientos, sus pensamientos, etc.

Sin embargo, resulta necesario poner el acento en otras interpretaciones que permitan fijar vías para que los contenidos de la representación, latentes en las sociedades actuales, puedan manifestar focalizaciones capacitadas para dar cuenta de procesos generativos y funcionales que, si bien hagan posible entender el género a partir de nuestras experiencias, también lo hagan a la estela de las informaciones, los conocimientos y los modelos de pensamiento que recibimos y trasmitimos a través de la educación y la comunicación social.

Así, demandar otra concepción de lo que debemos entender por «género» implica el desarrollo de un paradigma social más equitativo, preocupado por la reestructuración de ciertos valores y creencias con respecto al género y las relaciones de género, esto es, un cambio en la cosmovisión cultural sobre los géneros que se sustente en y que sea asumida por nuestra sociedad (Lagarde, 1996).

Venimos de una historia reciente en la que la marginación de las mujeres era habitual, donde la escuela incluso detarminaba las diferencias, de manera incuestionable, entre hombres y mujeres: la institución escolar segregada separaba a niños y niñas en los espacios escolares y también en aquello que tenían que aprender, mediante currrículums diferenciados (Villar, 2018). Pero en estas páginas nos queremos referir, entre otras muchas cosas, a la posibilidad de ir más allá de aceptar una mera educación mixta (donde niñas y niños comparten espacios), porque lo que hacemos es hablar de coeducación. La coeducación la entendemos como un sistema que apuesta por una educación sin sesgos sexistas, que tiene constancia de todos y cada uno de los procesos que subyacen en la construcción de las identidades femeninas y masculinas, que observa y denuncia las discriminaciones, que procura acabar con las limitaciones que reflejan los estereotipos de género y que también fomenta la educación en conocimientos, actitudes, valores y comportamientos en el desarrollo íntegro de las personas en el mundo laboral, en la vida familiar, laboral y en (co)participaciones ciudadanas de diversa índole.

Todo esto condiciona la función y la labor de las instituciones educativas, así como la implicación del profesorado como agente clave. En consecuencia, un objetivo fundamental del sistema educativo debe ser la articulación de contenidos didácticos que reafirmen las ideas de igualdad y libertad; unos contenidos basados en una noción de «derechos igualitarios» que transmitan al alumnado que únicamente se alcanza la equidad cuando las mujeres pueden acceder a todos los espacios ocupados tradicionalmente por los hombres. Así:

«esta propuesta la escuela debe centrarla tanto en la igualdad de oportunidades como en la eliminación de los prejuicios sobre la cultura de género, latentes en nuestra sociedad. En este sentido, autores como Barragán y González (2007) apuntan la necesidad de revisar la situación educativa planteada y prescrita en los currrículums educativos vigentes hasta ahora» (Pallarès, 2012, p. 191-192).

En una época como la actual, marcada por la galaxia tecnológico-digital, el hecho de que la acción educativa se ocupe de todo lo que hemos apuntado hasta ahora en esta introducción abre la posibilidad de proponer interacciones dialógicas que cimienten discursos (y que promuevan imágenes, iconos, etc.) establecidos en función de la equidad de género, que posteriormente tendrán que ser normalizados por una ciudadanía que, al vivir, al actuar y al representar todo lo que concierne a su día a día, tendrá la posibilidad de poner en evidencia los nuevos sentidos, es decir, las nuevas concepciones en torno al género que la sociedad tanto precisa.

Entendemos, pues, la coeducación como una pasión social esencial y una especie de obligación moral para el campo educativo, que debe forjar e impulsar determinados ámbitos de educación para que cada área sociocultural repercuta (positivamente) en el quehacer cotidiano de una escuela que 
necesita ser analizada como eje de actuación pedagógica y como ámbito de educación. De hecho, aquello a lo que hemos convenido en denominar como educación necesita construirse, en cada caso particular y en cada contexto determinado, en una sucesión de relaciones axiológicas: «valor-elección», «decisión-sentimiento», «obligación-autonomía», etc. Esto hace que educar requiera afrontar parámetros antropológicos, sociales y psicológicos atendiendo a rasgos distintivos de la idiosincrasia de la educación y del sentido de lo pedagógico, que canalizarán y concretarán, en cada acto educativo, su significado real, estableciendo las dimensiones de intervención, las competencias adecuadas, las capacidades específicas y las disposiciones básicas necesarias para cada momento educativo concreto.

La educación, a la postre, depende de nuestra actividad interna, que siempre debe ser guiada hacia finalidades, que son las que nos permiten generar ámbitos de educación y las que hacen posible integrar dichas finalidades dentro del eje formativo temporal, sobre todo a partir de aquellos parámetros que conforman la condición humana social, individual y de especie.

El objetivo nuclear de la coeducación es llegar a la vinculación entre iguales, reafirmando las diferencias individuales y valorando las aportaciones que los distintos colectivos de género, de clase, étnicos y culturales llevan a cabo (Blat, 1994). A raíz de esto, se puede afirmar que algunas de las demandas que se ponen encima de la mesa en los debates educativos actuales necesitan elementos de reflexión y pautas de acción sistematizada y con mentalidad y mirada pedagógicas. Precisamente por ello, en el presente monográfico se asume que la educación supone un contexto idóneo para el avance en la igualdad de oportunidades entre mujeres y hombres.

De esta manera, la coeducación se erige en una dimensión social capaz de cuestionar los condicionantes tradicionales de un modelo educativo que, en realidad, no siempre ha sido capaz de distinguir la igualdad de acceso a la educación de lo que se entendía como «la educación para la igualdad de oportunidades»; por eso, a la sociedad (en general) y a las Ciencias Sociales (más en particular), les queda, en el largo camino hacia la coeducación (y en otros muchos ámbitos) la tarea de afrontar retos que hagan posible la progresión de decisiones con sentido profesional en las funciones pedagógicas que se tienen que llevar a cabo en cada rincón de nuestros centros educativos. La tarea es, cuanto menos, apasionante, y cada uno de los artículos que componen este monográfico aporta un grano de arena al sentido educativo, constructivo y optimizante de la coeducación.

En el primer artículo Jordi Planella, Joxe Jiménez y Lucero Ruiz presentan una reflexión sobre aspectos relacionados con las maneras de transmitir saberes vinculados con el cuerpo, la educación y la perspectiva de género en el contexto universitario, y, de forma concreta, en la formación de profesionales de la educación. El estudio se lleva a cabo a partir de tres grandes categorías: Pedagogía Sensible, Transdiversidad y Postcolonialidad.

En el segundo artículo Ana Isabel Ugalde, Pilar Aristizabal, Beatriz Garay y Haritz Mendiguren analizan la situación de los centros de Vitoria-Gasteiz en relación a la coeducación. También estudian en qué medida son conocidas en estos centros las políticas coeducativas y su incidencia en el día a día de la escuela. Llegan a la conclusión de que la coeducación no es una prioridad en la escuela, por eso demandan una colaboración entre instituciones y una coordinación efectiva a la hora de proponer planes, también reclaman una red para compartir recursos entre los distintos agentes intervinientes, puesto que, en algunos de los centros analizados, constatan que la coeducación está muy lejos de las preocupaciones del profesorado.

El tercer artículo, de María Teresa Bejarano, Irene Martínez y Montserrat Blanco, analiza si la coeducación se ha asentado en los actuales planes de formación de los profesionales de la educación, así como en las nuevas iniciativas curriculares que van surgiendo. A través de un recorrido histórico por los avances de la coeducación en España, concluyen que la coeducación continúa siendo un reto a alcanzar, lo cual les lleva a proponer las pedagogías feministas como campo de acción transformador para la despatriarcalización del currículum.

En el cuarto artículo Maria Lozano y Liliana Aura desarrollan una reconceptualización de las competencias educativas para la coeducación y la educación para la paz, estableciéndolas como ejes vertebradores de una escuela inclusiva, democrática y emancipadora. La conclusión a la que llegan es que se hace necesario reclamar una distinción entre espacio público y espacio privado, y también la incorporación de la dialéctica entre la ética de la justicia y la ética del cuidado como aspectos esenciales a implementar en el desarrollo de las prácticas coeducativas.

En el quinto artículo Amaia Álvarez, María Teresa Vizcarra y Gema Lasarte se aproximan a cómo se entiende el término coeducación y a cuál ha sido su evolución. A partir de una investigación centrada en 30 centros escolares de Vitoria-Gasteiz, desarrollada mediante cuestionarios a profesorado 
y grupos de discusión con familias, profesorado y alumnado, se recopilan distintas concepciones sobre la coeducación. Los resultados evidencian que es necesaria una actualización conceptual, porque este término sigue asociado a la escuela mixta y a un concepto de igualdad basado en un sistema binario, y no se vincula, en cambio, con otras opciones más recientes relacionadas con la feminización del conocimiento o la visibilización y la valoración de la diversidad.

En el sexto artículo Begoña Sánchez y Zulema Barea analizan la formación inicial en materia de coeducación que posee el alumnado del Grado de Educación Primaria de la Universidad de Cádiz. Los resultados ponen de relieve que el alumnado posee escasa formación en coeducación. Este hecho les lleva a plantear propuestas de intervención prácticas para favorecer el camino de la coeducación en nuestras escuelas mediante la formación inicial del profesorado.

\section{Referencias}

Barragán, F. \& González, J. (2007). La construcción de la masculinidad en los contextos escolares. Revista de Investigación educativa, 25(1), pp. 167-183.

Blat Gimeno, A. (1994) Informe sobre la igualdad de oportunidades educativas entre los sexos, Revista Iberoamericana de Educación, 6, pp. 123-145.

Espejo, R. L. (2010). Representaciones sociales sobre identidad de género. Entre Comillas, 13(1), pp. 62-80.

Lagarde, M. (1996). Género y feminismo. Desarrollo bumano y democracia. Madrid: Horas y Horas.

Pallarès, M. (2012). La cultura de género en la actualidad: actitudes del colectivo adolescente hacia la igualdad. Tendencias Pedagógicas, 19, pp. 189-210.

Villar, A. (2018). Reseña de Coeducación, apuesta por la libertad. Revista de Sociología de la Educación, 11(1), pp. 186-188. doi: http://dx.doi.org/10.7203/RASE.11.1.11345 